\title{
Remifentanil and hydrogen peroxide-induced oxidative stress on human keratinocytes
}

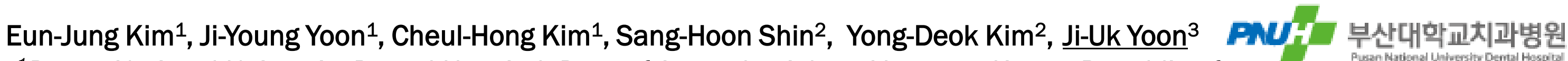

${ }^{1}$ Pusan National University Dental Hospital, Dept of Anaesthesiology, Yangsan, Korea, Republic of,

${ }^{2}$ Pusan National University Dental Hospital, Dept of Surgery, Yangsan, Korea, Republic of

${ }^{3}$ Pusan National University Yangsan Hospital, Dept of Anaesthesiology \& Pain Medicine, Yangsan, Korea, Republic of,

\section{Background}

Many patients suffer from wound healing problems after surgery. During wound healing process, reactive oxygen species (ROS) are produced and overfull ROS are detrimental to wound repair because of their high reactivity. Remifentanil can decrease the production of ROS and inflammatory response. Therefore, we investigated the effects of remifentanil on human keratinocytes(HaCaT cell) during $\mathrm{H} 2 \mathrm{O} 2$-induced oxidative stress and whether this effect has connection with autophagy.

\section{Materials and Method}

Human keratinocytes (HaCaT cell line) were randomly assigned to 4 groups: control group, cells incubated in normoxia without remifentanil; H2O2 group, cells exposed to $\mathrm{H} 2 \mathrm{O} 2(300 \mu \mathrm{M})$ for $2 \mathrm{~h}$; remifentanil pretreatment (RPC) $+\mathrm{H} 2 \mathrm{O} 2$ group, cells pretreated with remifentanil $(1 \mathrm{ng} / \mathrm{mL})$ for $2 \mathrm{~h}$ and exposed to $\mathrm{H} 2 \mathrm{O} 2$; and 3-methyladenine (MA) + RPC + H2O2 group, cells pretreated with 3-MA (1 mM) for $1 \mathrm{~h}$ and exposed to remifentanil, H2O2. MTT assay was conducted to analyze cell viability. Apoptosis was measured via Hoechst staining. A wound healing assay was used to measure cell migration. The role of autophagy was ascertained using autophagosome staining.

\section{Results}

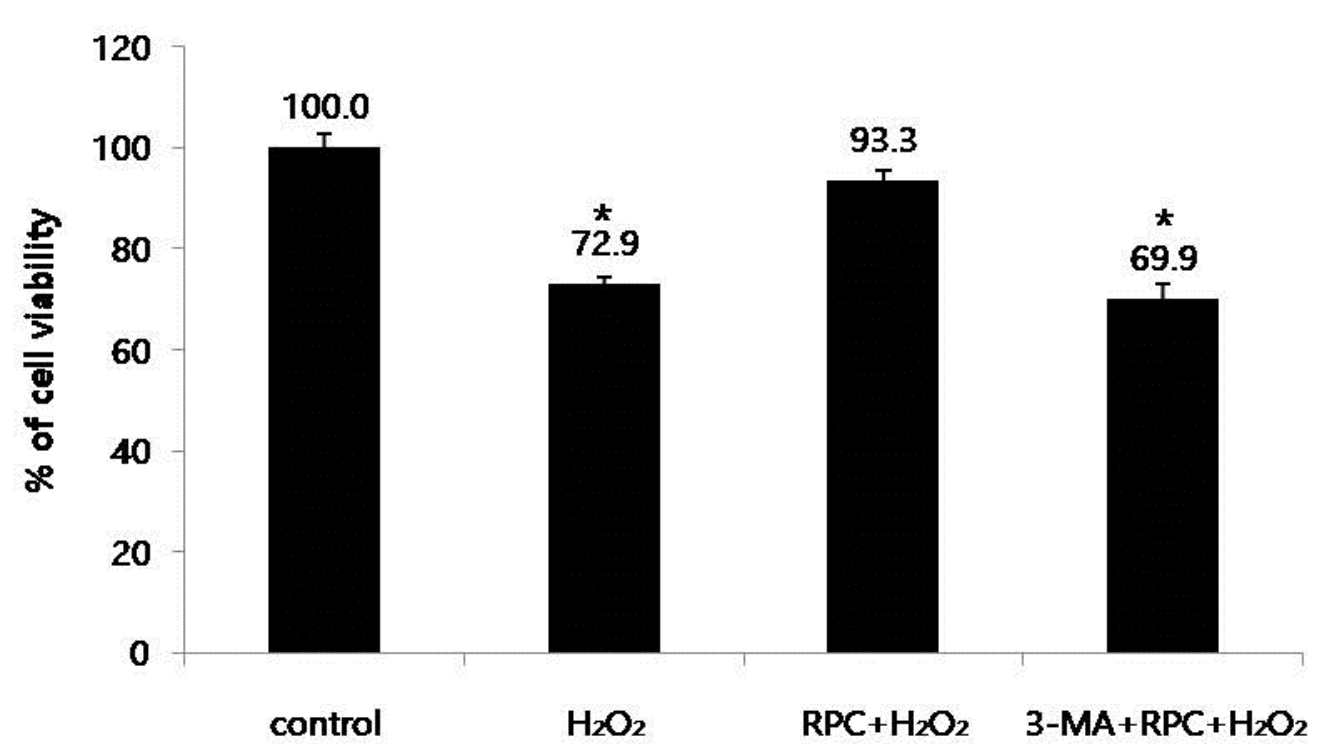

Fig. 1. Cell viability with MTT assay

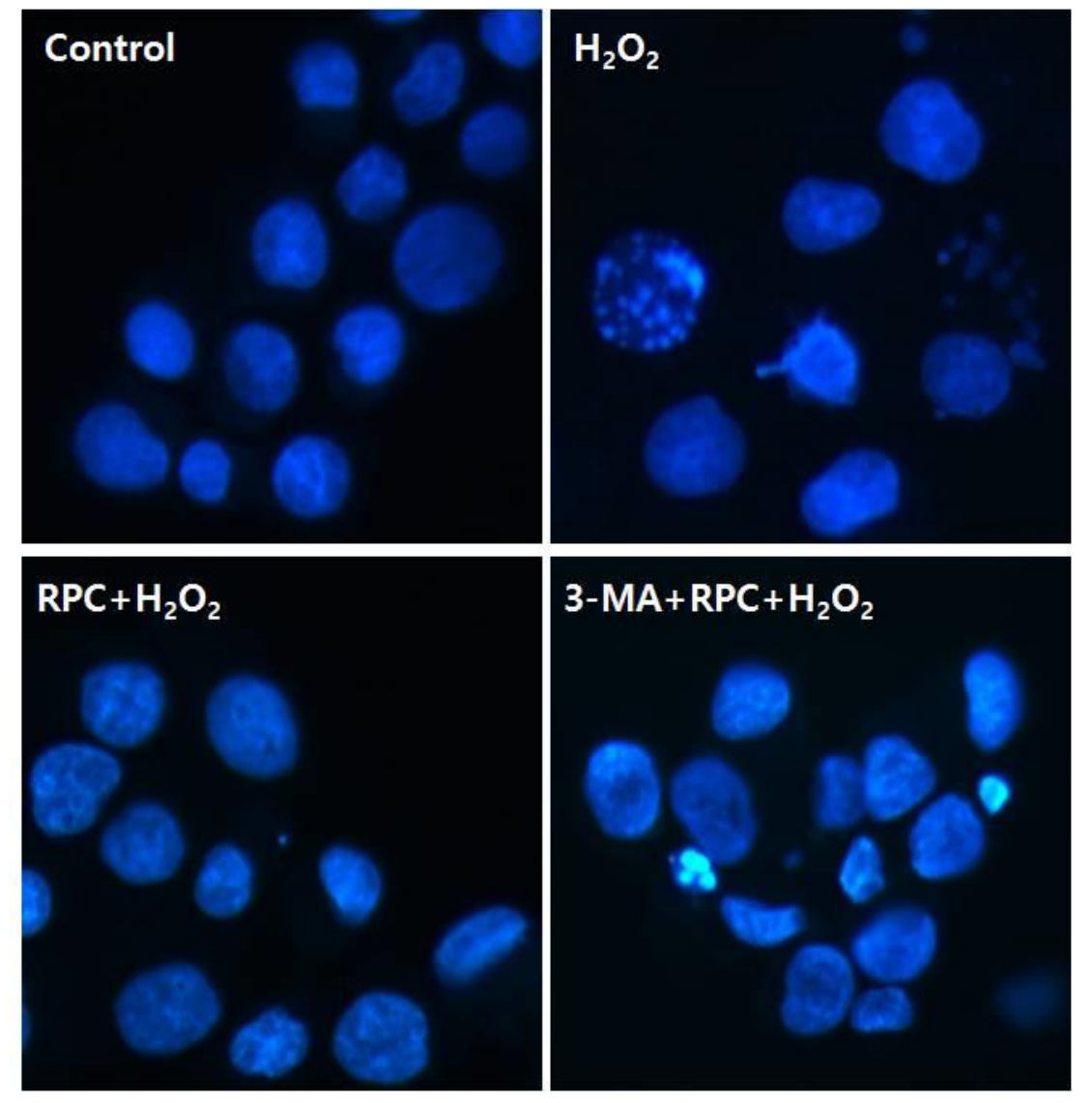

Fig. 3. Cell apoptosis was evaluated by apoptotic nuclei staining with Hoechst 33342
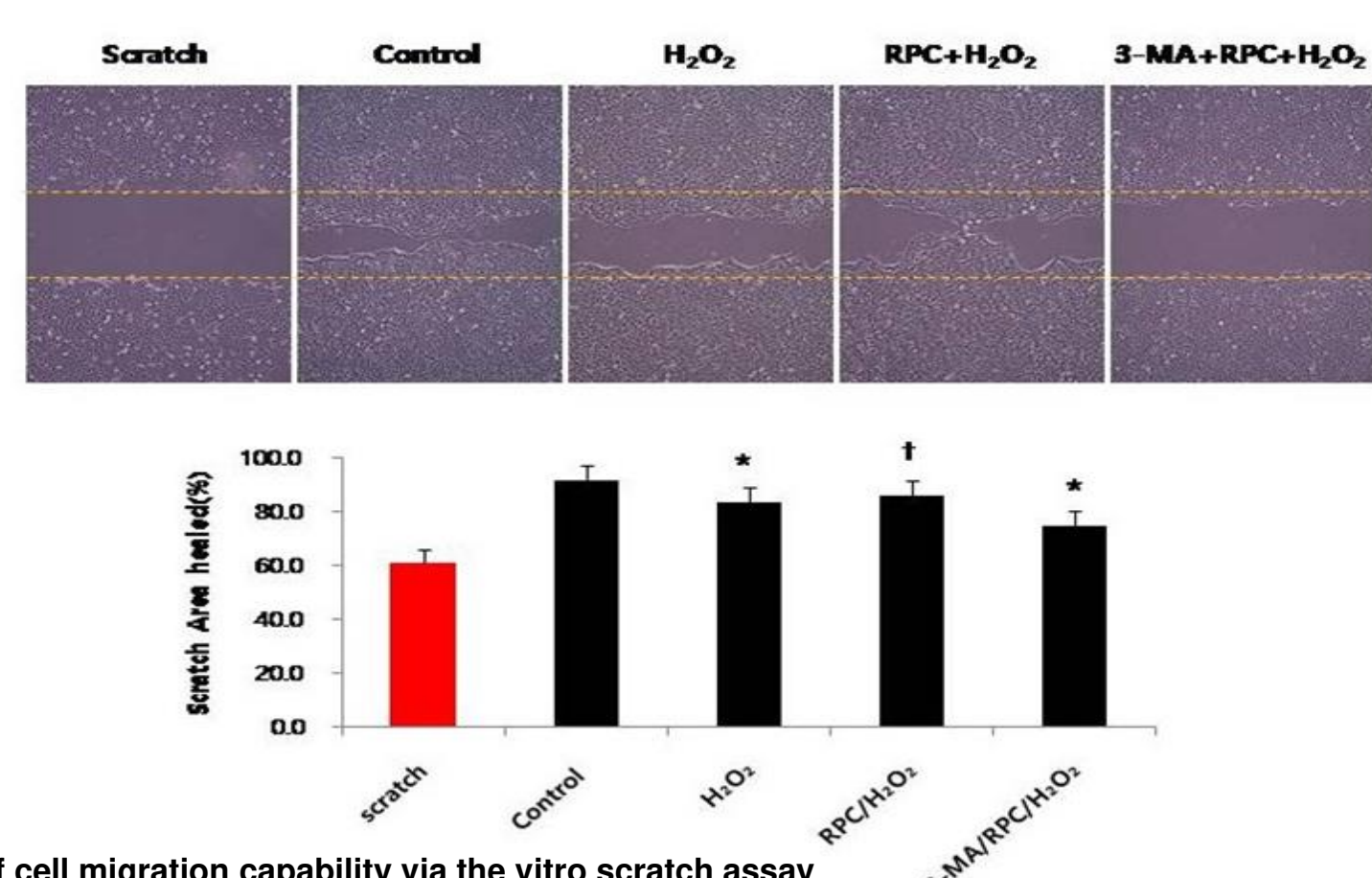

Fig. 2. Investigation of cell migration capability via the vitro scratch assay

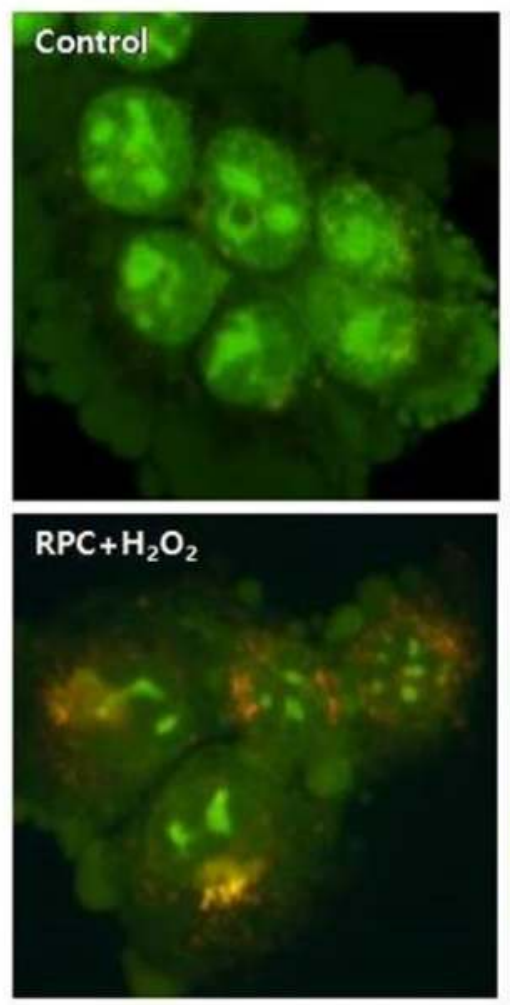

Fig. 4. Acridine orange staining of autophagosomes

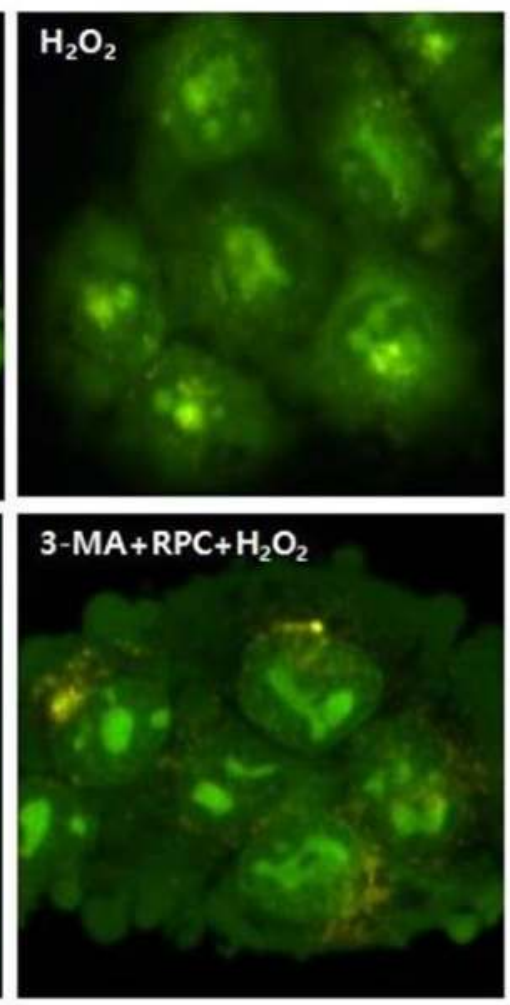

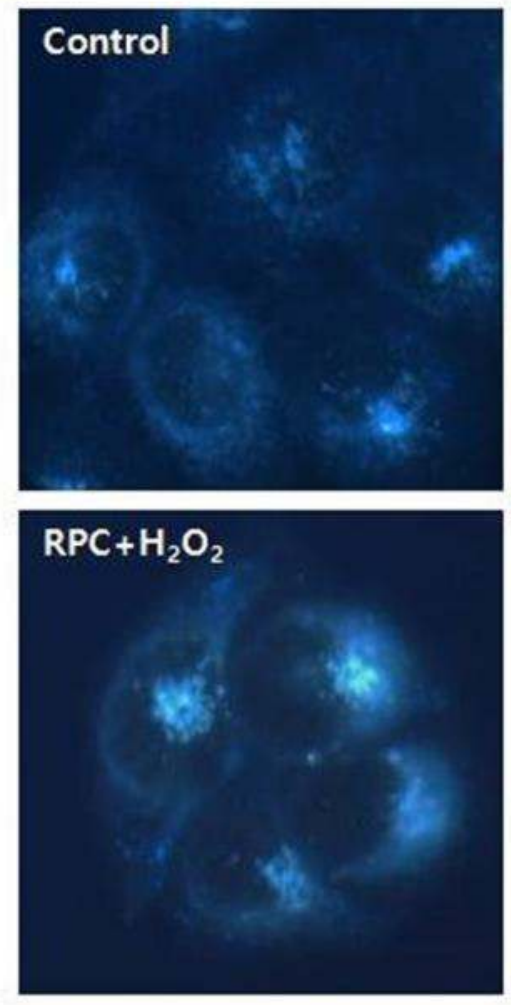

Fig. 6. Monodansylcadaverine staining for autophagic vacuoles

\section{Conclusions}

Cell viability significantly decreased in $\mathrm{H} 2 \mathrm{O} 2$ group and improved by RPC. RPC effectively decreased H2O2-induced apoptosis in HaCaT cell. Remifentanil restore cell proliferation and migration injuried by $\mathrm{H} 2 \mathrm{O} 2$. However, 3-MA inhibited the protective effect of remifentanil at cell apoptosis. 